\title{
Keeping pace with social media technology: Implications for the mental health of individuals with neurological conditions
}

\author{
Kelly Ravenek and Mike Ravenek
}

\section{University of Western Ontario}

The ever-changing face of technology makes it difficult for anyone to keep up with the latest and greatest offered to consumers.With advances in social media, the means by which people can communicate with others electronically has grown exponentially in the last decade. Wikipedia, Twitter, YouTube, Skype, Google+ and Facebook are now household names. This has important implications for those living with chronic illness, given that many health consumers actively seek information, advice and support one another via online venues. ${ }^{1}$ In fact, numerous support organizations for individuals with neurological conditions now have their own Twitter, YouTube and Facebook pages. Patient groups, such as those in Canada with multiple sclerosis, have already provided a concrete example of how social media technologies can be used to influence research priorities and how research findings should be disseminated. ${ }^{2}$ So, what impact can these technologies have on mental health? To begin to address this question, we will draw on examples and reflections from our current doctoral research programs.

Parkinson's disease (PD) and spinal cord injury (SCI) are divergent in their pathology and prognosis, one being a progressive neurological condition with no known cause (in its idiopathic form) and one being an acquired injury. Both, however, can happen to the young or the old, impose functional limitations and have associated mental health concerns. In terms of mental health concerns, depression, stress and isolation are among the most frequently encountered, especially among young adults with $\mathrm{PD}$ and $\mathrm{SCl}{ }^{3-6}$

K. Ravenekand colleagues at Parkwood Hospital in London, Ontario are currently using video conferencing and gaming technology to remove barriers to exercise for individuals with $\mathrm{SCl}$. Exercise has a number of benefits for those with $\mathrm{SCl}$, including decreased depression, pain and stress. ${ }^{7,8} \mathrm{In} \mathrm{K}$. Ravenek's research, video conferencing technology is being used not only to deliver a real-time seated aerobic exercise program but also to deliver exercise counselling while avoiding transportation and environmental barriers. As stated by one participant, "I live in a small community and I know there are not a lot of resources for me; most of the classes I go to now are 20-30 minutesaway, so doing this in my home is fantastic ... the people are great and it's fun". ${ }^{\prime}$ As alluded to by this participant, in addition to the benefits of exercise this technology allows for an interactive and social experience both with a trained instructor and peers.

The social benefits of technology have also been observed in M. Ravenek's research which investigates the diagnosis experiences and information needs of young adults with PD. More specifically, M. Ravenek is using a private onlinediscussion board and YouTube Channel as adjuncts to other forms of data collection. With both of these technologies, participants are able to anonymously and asynchronously (i.e., available 24 hours per day) interact with one another and continue to provide input on the developing results of the project. However, participants have also started to use the discussion board as a means of providing informal support and encouragement to one another. Although measuring depression, stress and isolation was not a focus of this study, participants have provided anecdotal support to warrant a closer examination of the impact of social media on these health issues. Some evidence to suggest that homogeneous PD support groups can improve symptoms of depression has already been reported by Lieberman et al. ${ }^{10}$

Implementation of any new or existing technology warrants many considerations. Participant training is key to promote engagement and to retain interest in the technology being used. Training must also incorporate the 'lingo' associated with the various social media technologies (e.g., friending, threads, tweeting, etc.). Privacy issues must also be addressed. The video conferencing intervention and discussion board, that are part of our research 
C programs, allow participants to choose an anonymous username. It is also important to comment on the role of monitoring and moderating. The video conferencing technology incorporates in-home monitors as a safety mechanism during all exercise classes. The discussion board is moderated on a regular basis to respond and expand on posts as well as to ensure that appropriate content is submitted.

Social media technologies are, for all intents and purposes, a relatively low-cost option to allow people with neurological conditions to communicate with and support one another. Online support groups and video conferencing are only the tip of the proverbial social media iceberg, and future work should investigate what services individuals are using, how they are using them, and why they are using them. In addition to these contextual questions, there is also a need for evaluation of their effectiveness. ${ }^{1}$ It is, therefore, not a question of whether people with neurological conditions are using social media technologies, but how we may incorporate these technologies into our research to evaluate their impact and benefit to those living with a neurological condition.

\section{References}

1. Eysenbach G, Powell J, Englesakis M, Rizo C, Stern A. Health related virtual communities and electronic support groups: systematic review of the effects of online peer to peer interactions. BMJ. 2004 May 15;328(7449):1166.

2. Chafe R, Born KB, Slutsky AS, Laupacis A. The rise of people power. Nature. 2011;472(7344):410-411.

3. Craig A, Tran Y, Middleton J. Psychological morbidity and spinal cord injury: a systematic review. Spinal Cord. 2009 Feb;47(2):108-114.

4. Post MW, van Leeuwen CM. Psychosocial issues in spinal cord injury: a review. Spinal Cord. 2012 May;50(5):382-389.

5. Schrag A, Hovris A, Morley D, Quinn N, Jahanshahi M. Young- versus older-onset Parkinson's disease: Impact of disease and psychosocial consequences. Movement Disorders. 2003;18(11):1250-1256.

6. Gupta A, Bhatia S. Psychological functioning in patients with Parkinson's disease. Parkinsonism \& Related Disorders. 2000;6(3):185-90.

7. Hicks A, Martin K, Ditor D, Latimer A, Craven C, Bugaresti J, et al. Longterm exercise training in persons with spinal cord injury: effects on strength, arm ergometry performance and psychological well-being. Spinal Cord. 2003;41(1):34-43.

8. Martin Ginis KA, Latimer AE, McKechnie K, Ditor DS, McCartney N, Hicks $A L$, et al. Using exercise to enhance subjective well-being among people with spinal cord injury: The mediating influences of stress and pain. Rehabilitation Psychology. 2003;48(3):157-64.

9. CTV Lifetime. Fitness Frontiers London, ON March 28, 2012. Available from: http://londonlifetime.wordpress.com/2012/03/28/fitness-frontiers

10. Lieberman MA, Winzelberg A, Golant M, Wakahiro M, DiMinno M, Aminoff $M$, et al. Online support groups for Parkinson's patients: a pilot study of effectiveness. Soc Work Health Care. 2005;42(2):23-38.

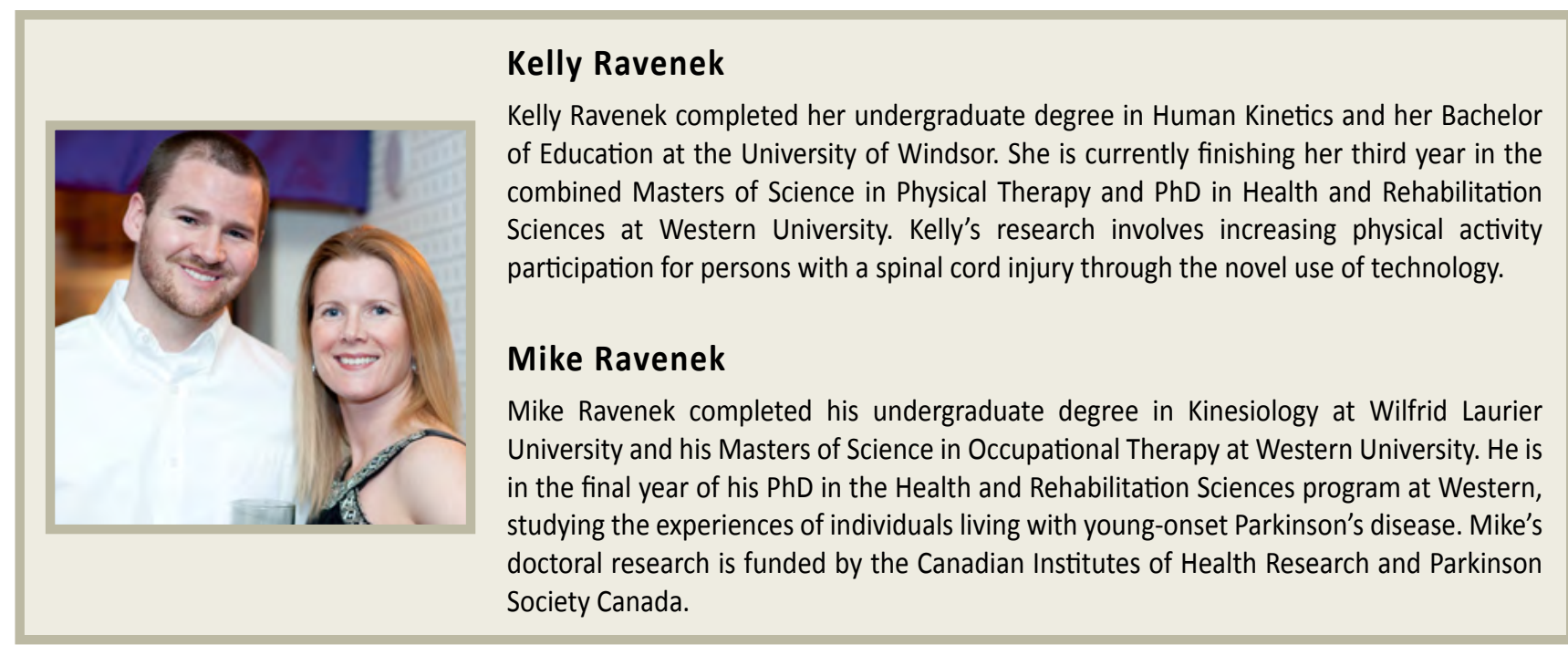

